A

Ponceau S protein signal curve

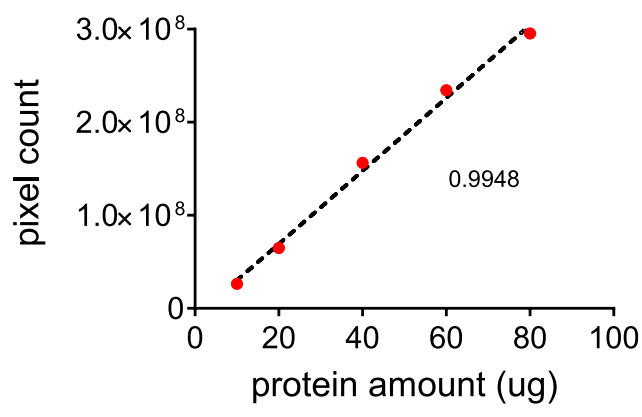

B

AcK 10 days $\mathrm{Al}$

endo/trans-

endo-

func

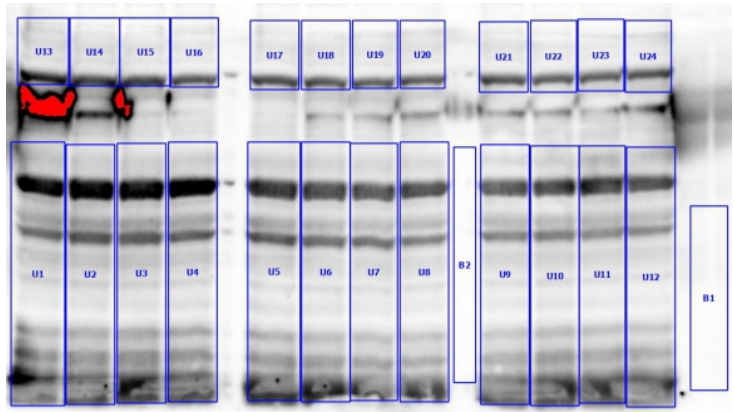

AcK 6 days Al

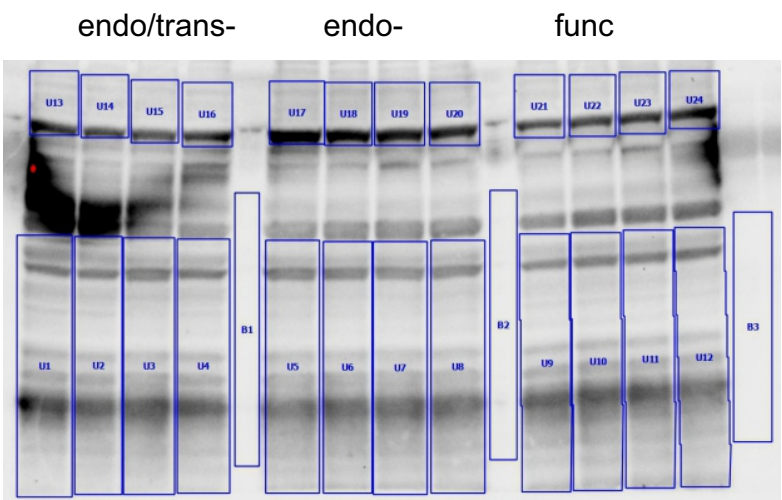

$\mathrm{acH} 3$

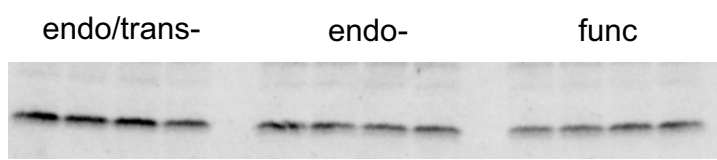

$--1-\cdots+\cdots$

\section{Ponceau S}

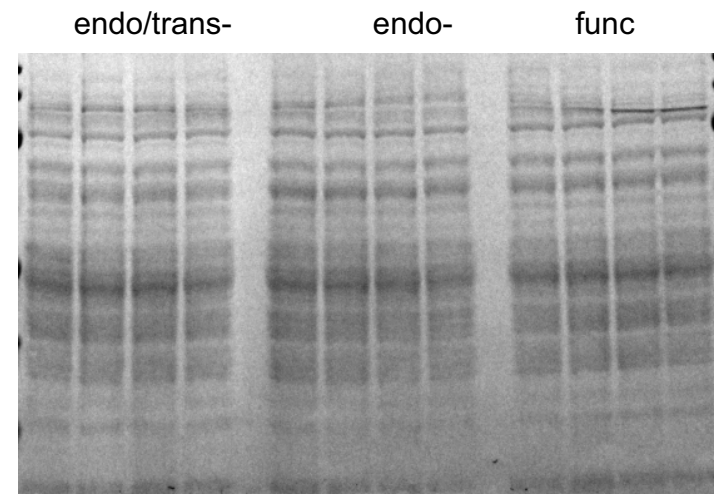

\section{Ponceau S}

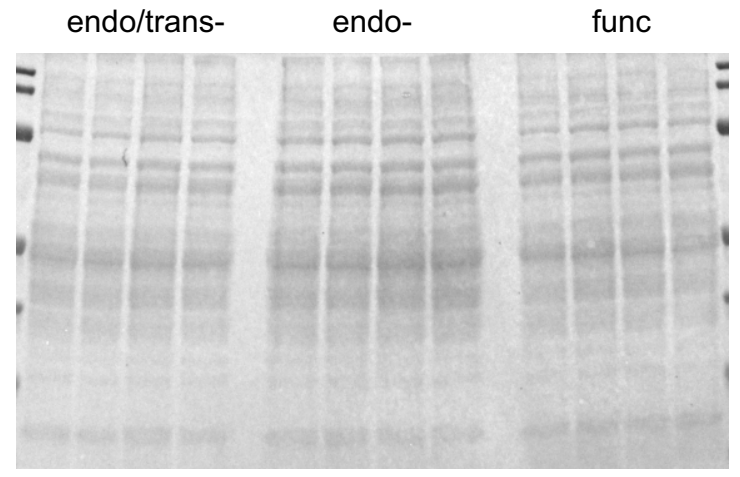

H3

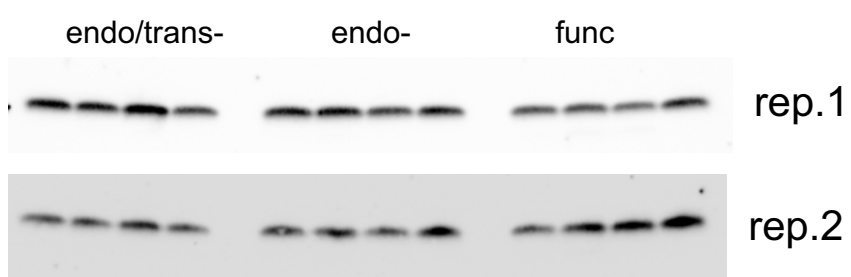


AcK mito 10 days $\mathrm{Al}$

endo/trans-

endo-

func

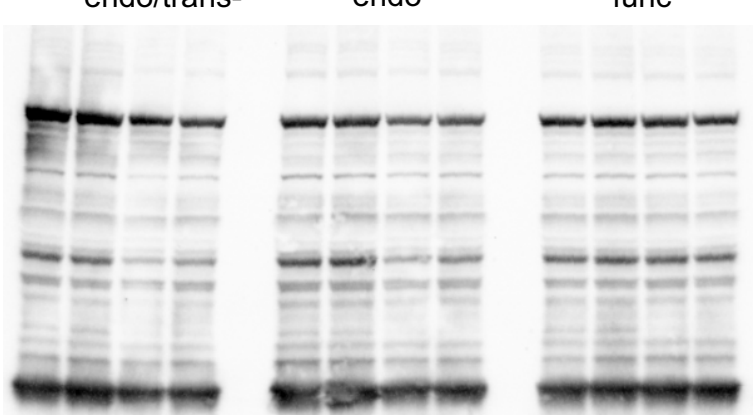

\section{PARylation 6 days AI}

endo/trans- -

func

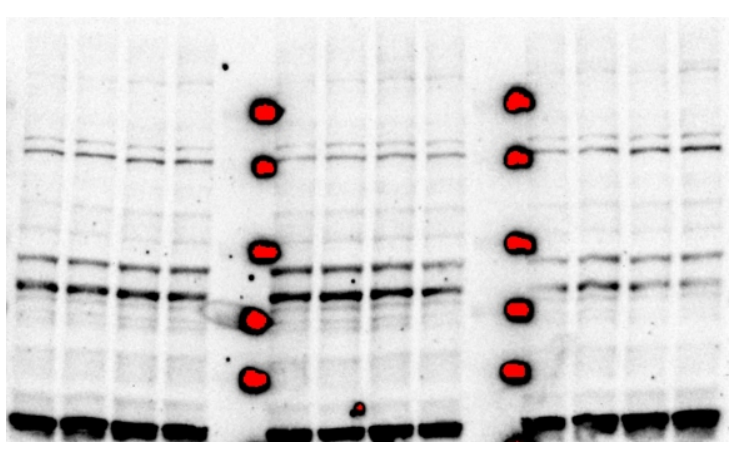

PARylation 10 days AI

endo/trans-

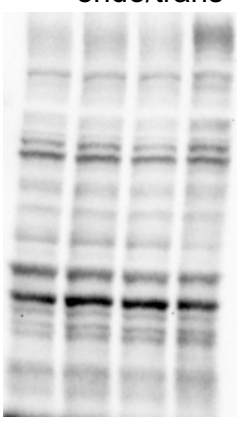

endo-

func

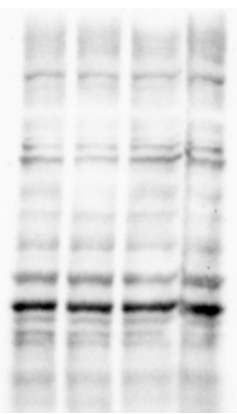

NDUFS3 mito 10 days Al

endo/trans-

endo-

func

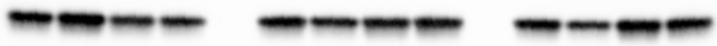

Ponceau S

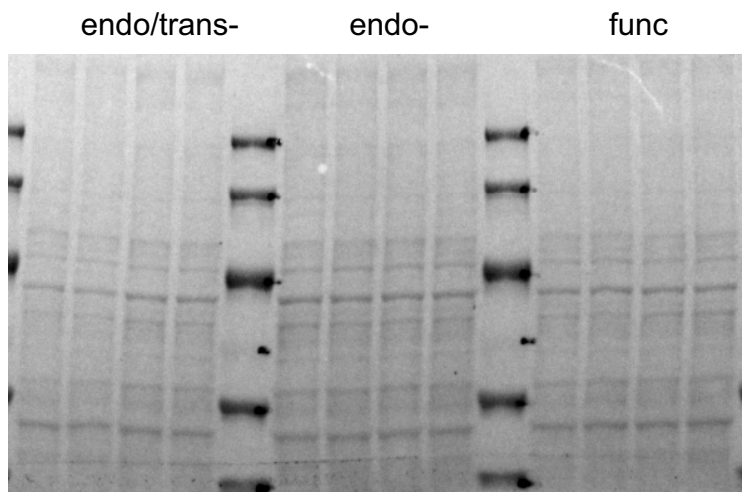

\section{Ponceau S}
endo/trans-
endo-
func

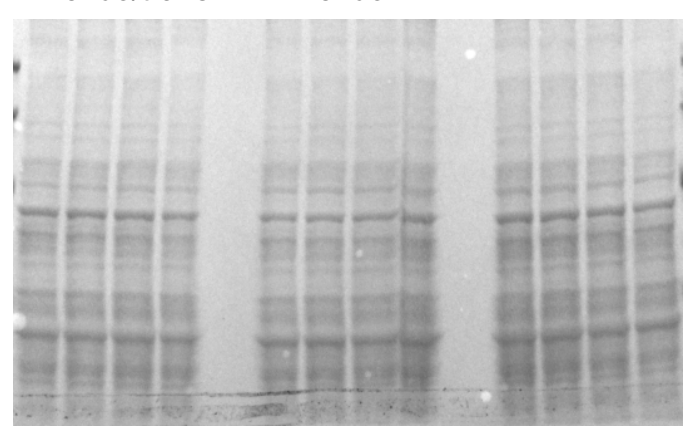




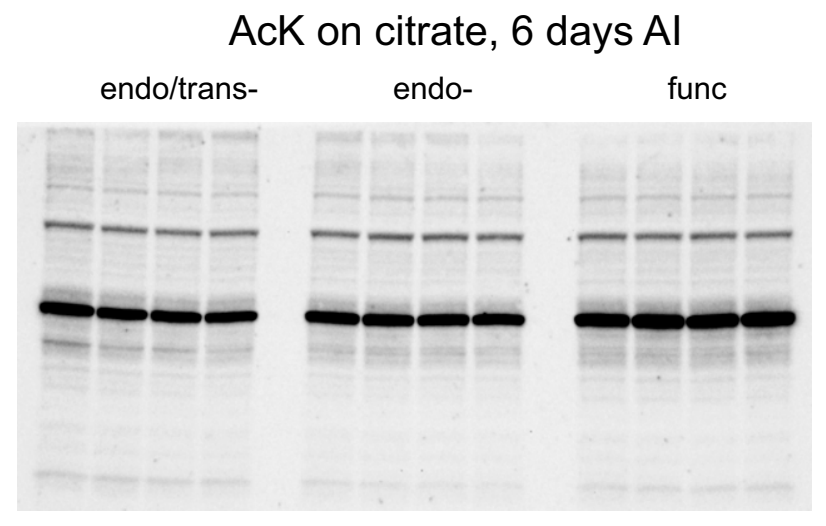

AcK on citrate, 10 days $\mathrm{Al}$ endo/transendo-

func

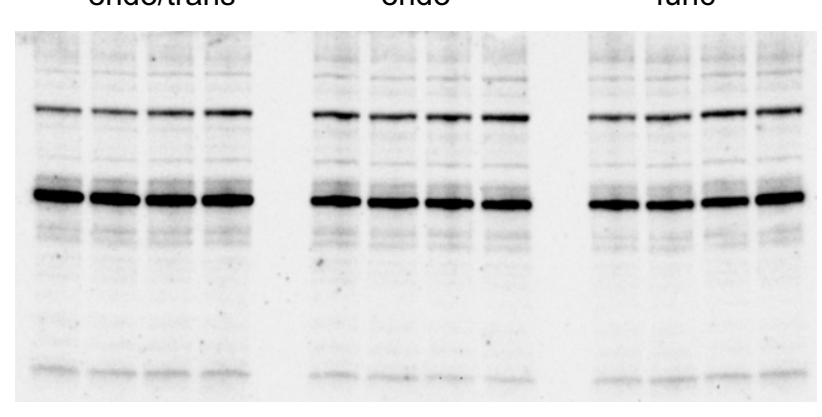

\section{Ponceau S}

endo-

func

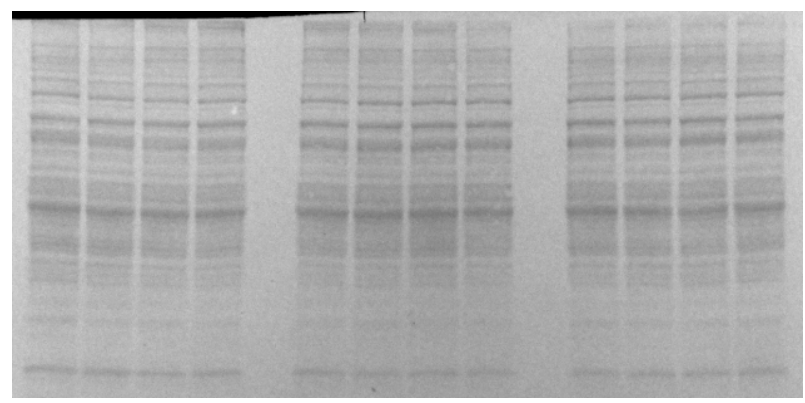

Ponceau S

endo-

func

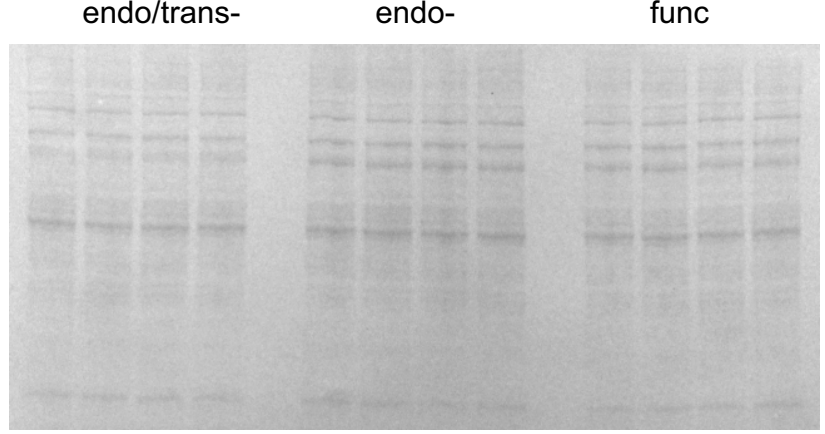

C
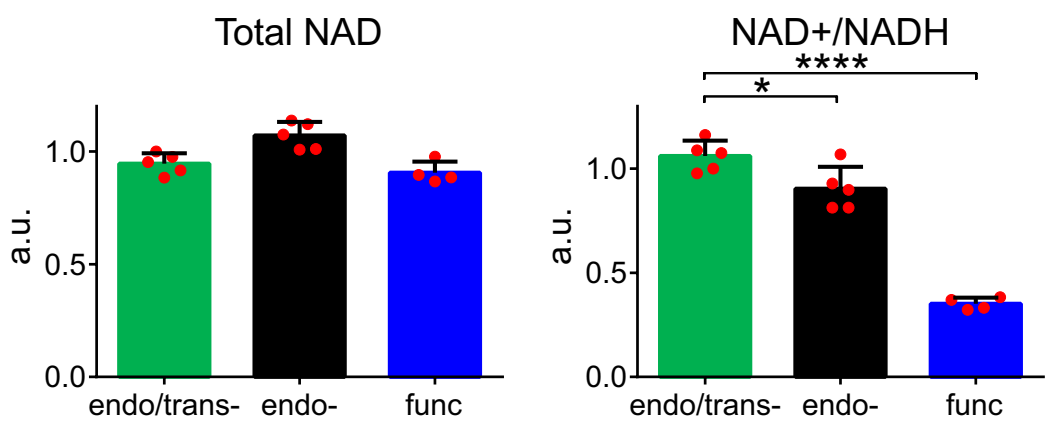